\title{
Breast conserving surgery and intra-operative specimen radiography: Margin assessment by the surgeon or the radiologist?
}

\author{
Senthurun Mylvaganam ${ }^{1 *}$, Habib Tafazal ${ }^{1}$, Virginia Caddick ${ }^{2}$ and Priya Madahar ${ }^{1}$ \\ ${ }^{1}$ Department of Breast Surgery, Royal Wolverhampton Hospitals NHS Trust, New Cross Hospital, Wolverhampton, UK \\ ${ }^{2}$ Department of Plastic Surgery, Queen Elizabeth Hospital, Birmingham, UK
}

\begin{abstract}
In the United Kingdom since the late 1990s there has been both a shortage of and falling level in recruitment of breast radiologists/radiographers. Specimen radiography is a widely used intra-operative adjunct to aid margin assessment in patients undergoing wide local excision for early stage breast cancer.

Aim: This study looks to determine accuracy and congruence of radiological intra-operative margin assessment by surgeon and consultant radiographer against the gold standard of histological assessment.

Method: Prospective assessment of specimen margins for all wide local excisions performed between June 2015 and June 2017 by a single breast surgeon in the UK. Specimen radiographs were independently assessed by a consultant radiographer and surgeon for adequacy of margins and compared to histological assessment.

Result: Both surgeon and consultant radiographer had an equal sensitivity of 33\%, and specificity of $63 \%$ versus $73 \%$. Negative predictive values were 89.2 (surgeon) vs 90.5 (radiographer). There was fair agreement between surgeon and radiographer $(\mathrm{kappa}=0.252)$

Discussion: The accuracy of margin assessment by the radiologist in this study is similar to current literature. There is agreement between surgeon and radiographer and a high negative predictive value observed for both in $\mathrm{x}$-ray interpretation suggesting equivalence of assessment and high confidence in evaluating negative margins. With the current UK trend of increasing radiology specific breast disease workload and recruitment deficit, a surgeon margin assessment only of the specimen $\mathrm{x}$-ray may more optimally utilise radiology time without compromising re-operation rates.
\end{abstract}

\section{Introduction}

Breast conserving surgery (BCS) is a safe, effective and widespread treatment for the management of early stage breast cancers [1-3]. The purpose of BCS is to remove the cancer with an effective margin ${ }^{4}$ whilst maintaining the cosmetic appearance of the breast $[5,6]$. For control of local recurrence, excision with clear margins has established importance [7]. Local recurrence has also been shown to impact on overall survival with the Early Breast Cancer Triallists' Collaborative Group concluding that avoiding four local recurrences prevents one breast cancer related death when other causes of death are excluded $[8,9]$.

The UK National Health Service (NHS) breast screening programme, by detecting cancers early in their natural history, often identify clinically impalpable lesions [10-11]. This presents unique challenges to the surgeon particularly in intra-operative assessment of adequacy of excision. Radiologically positioned wire guidance and ultrasound marking are established interventions to aid the surgeon in localizing clinically impalpable lesions [12-16]. Different modalities have been employed to subsequently assess intra-operative adequacy of excision margins. Specimen mammography is one assessment modality, which has been found to be useful but not always reliable for detecting margin involvement [17-19]. The literature shows some variation with negative predictive values as low as $32 \%$ and sensitivity up to $62 \%$ for radiologically detecting tumour at the margins [20]. A specimen X-ray, which correctly interpreted as identifying a clear or close/involved margin intra-operatively allows the surgeon to undertake where necessary a margin cavity shave at the same operation to increase the chance of a histologically clear margin at the first operation.

The Royal College of Radiologists (RCR) has recently reported that there is a "looming workforce crisis facing breast cancer screening and diagnostic services" in the NHS [21]. According to a recent RCR survey shortages are so common that almost one in $10(8 \%)$ consultant posts in NHS breast radiology services are unfilled and a quarter of breast cancer screening programme units operate with just one or two breast radiologists [22,23].

This is not a recent phenomenon and this shortage in specialist breast radiologists in recent years has prompted the emergence of consultant radiographers to maintain double reading and perform tasks to an equivalent competency as breast radiologists [24]. The ability of the radiographer to identify abnormalities on screening mammograms

${ }^{\star}$ Correspondence to: Senthurun Mylvaganam, Consultant Oncoplastic Breast Surgeon, Department of Breast Surgery, Royal Wolverhampton Hospitals NHS Trust, New Cross Hospital, Wolverhampton, UK, Tel: +447779303447; E-mail: seni@doctors.org.uk

Key words: breast disease, margin assessment, intra-operative specimen radiography

Received: May 10, 2018; Accepted: May 22, 2018; Published: May 25, 2018 
has been demonstrated in several studies [25]. When compared to radiologists the radiographers have higher false positive rates, but similar sensitivity [26-28]. Furthermore, trained radiographers have been shown to perform as well in the clinical setting [29].

In our institution specimen mammography is employed intraoperatively to guide adequacy of excision margins. The mammogram is reviewed by the operating surgeon intra-operatively but not routinely by a consultant breast radiologist/radiographer although it is subsequently reported on postoperatively.

This study looks to determine the accuracy of intra-operative radiological margins assessment by surgeon and radiologist against the gold standard histological assessment. We also aim to evaluate the effectiveness of intra-operative radiological assessment for achieving clear margin resections of breast tumors at first operation.

\section{Method}

All patients requiring BCS for invasive or pre-invasive breast disease performed by a single oncoplastic breast surgeon within the breast surgery department of the Royal Wolverhampton Hospitals NHS trust between June 2015 and June 2017 were recruited. Each excised breast lesion was orientated by sutures and titanium clips to identify the superior, medial and lateral aspects as shown in Figure 1.

For each case, a single view intra-operative specimen mammogram was performed using a Faxitron (Biovision, 24 inch $3.7 \mathrm{Mp}$ high resolution monitor) and commented upon by the operating surgeon as shown in Figure 2.

The mammogram was independently commented upon by a single dedicated consultant breast radiographer postoperatively. The surgeon or consultant radiographer commented on any one or multiple margins as being clear, or close/involved, based on the intraoperative radiological image. The consultant radiographer read the images on a 30-inch Barco Monitor (6Mp resolution). Standard surgical practice was for further margin cavity shaves where the specimen $\mathrm{x}$-ray was interpreted as close or involved. Where any defect was left following surgical excision, as necessary patients had breast parenchyma mobilization to close those defects. Oncoplastic techniques were therefore employed to ensure cosmetic satisfaction in all cases.

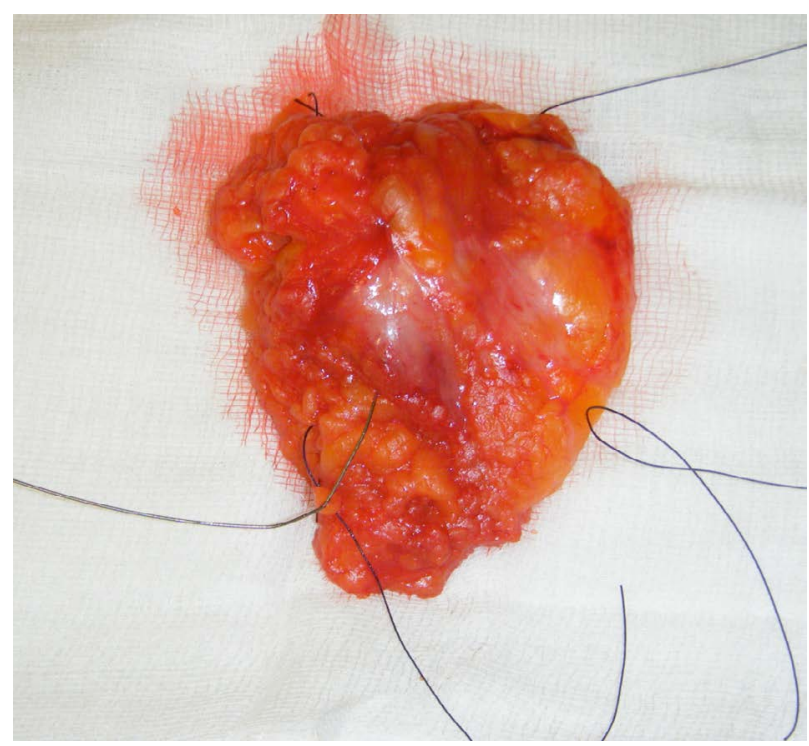

Figure 1. Breast Specimen orientated with sutures

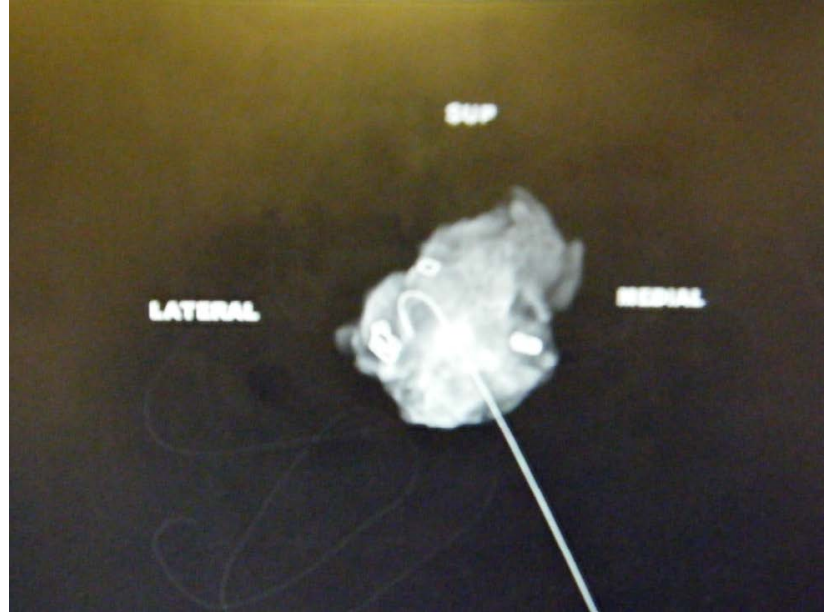

Figure 2. Single view specimen mammogram

The standard for a clear margin according to local protocol is equal to or greater than $1 \mathrm{~mm}$ as reported following histological assessment. Data was collected on histological type, size and grade of tumour and the outcome of whether further adjuvant treatment and/or surgery was recommended following discussion at the multidisciplinary meeting. Data was also collected on whether further cavity excisions were performed by the surgeon following intra-operative radiological assessment and the subsequent histological assessment of those cavity excisions independently of the original excision.

\section{Ethical approval}

As a survey of practice where institution standard patient treatment pathways were adhered to following consultation with local ethics committee no formal ethical approval was required for this study.

\section{Result}

59 consecutive patients operated on by a single breast surgeon were recruited. Lesions were either palpable $(n=36)$ or localised with the aid of radiologically placed wire guidance $(n=23)$.

Table 1 details the breast disease treated in this series.

Figure 3 shows the agreement of surgeon and radiologist assessment of margins with the histological assessment.

The results identified surgeon and radiological sensitivity of 33.33\% (CI $4.33-77.72 \%$ for both). Surgeon specificity was $63.46 \%$ (CI 48.96 76.38 ) versus a radiologist specificity of $73.08 \%$ (CI 58.98-84.43). The surgeon positive predictive value (PPV) was $9.52 \%$ (CI $3.11-25.65 \%$ ) and negative predictive value (NPV) $89.19 \%$ (CI of $81.88-93.78 \%$ ). Radiologist PPV was $12.50 \%$ (CI 4.06-32.54\%) and NPV 90.48\% (CI of $84.05-94.48 \%$ ).

Agreement of surgeon and radiologist with histological assessment was calculated using Cohen's kappa coefficient. Surgeon agreement with histological assessment was found to be $\mathrm{k}=-0.015$ (no agreement) and radiologist $\mathrm{k}=0.0367$ (slight agreement). The agreement between surgeon and radiologist assessment was calculated to be $\mathrm{k}=0.252$ (fair agreement). The agreement between surgeon and radiographer though from a patient perspective is most important. The poor agreement seen between surgeon and radiographer to histological assessment can be largely attributed to the low positive predictive value of each of these clinicians. However, it is the negative predictive value that most impacts patient care as it will directly relate to the need for a second operation. 
Table 1. Prevalence of the breast disease treated

\begin{tabular}{|c|c|}
\hline Histology & No. of patients \\
\hline DCIS ALONE & 1 \\
\hline High grade & 56 \\
\hline INVASIVE & 21 \\
\hline Ductal & 22 \\
\hline Ductal + DCIS & 1 \\
\hline Ductal + papillary & 7 \\
\hline Lobular & 1 \\
\hline Lobular + DCIS & 1 \\
\hline Mucinous & \\
\hline Metaplastic & \\
\hline Benign lesion & \\
\hline Papilloma & \\
\hline Adenomyoepithelioma & \\
\hline
\end{tabular}

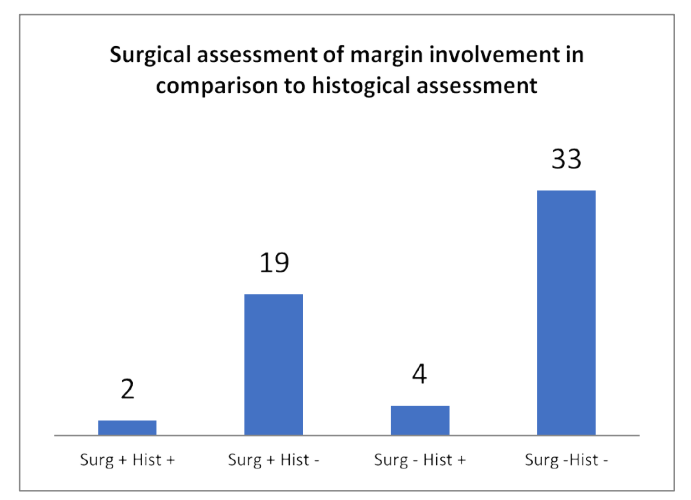

Radiological assessment of margin involvement in comparison to histogical assessment

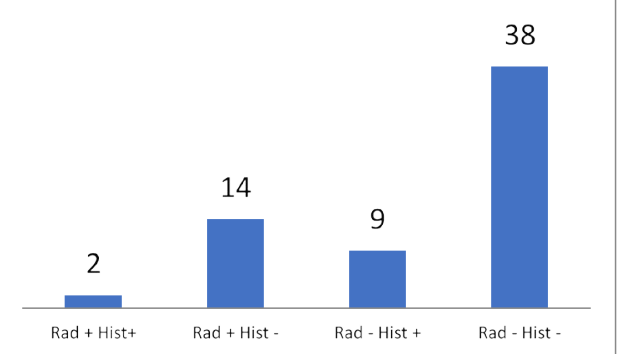

Figure 3. Surgeon and Radiologist Assessment against Histological assessment (Figure 3a Surgical assessment; figure 3b radiological assessment).

The surgeon and radiographer had a high negative predictive value of margin assessment and so rightly did not advocate further margin cavity shaves at first operation and also correctly predicted a clear margin so avoiding a second operation.

22 patients in this study (37.3\%) underwent further margin cavity shaves at first operation following surgeon assessment of specimen radiography. 2 of these patients had histologically close margins from the initial excision specimen. Of the 37 patients whose radiological margins had been assessed as clear by the surgeon 3 needed a second surgery for excision of margins (1 DCIS at margin, 2 invasive). Out of the 16 patients assessed as close/involved by the consultant radiographer 1 patient needed further surgery for margins. The 42 patients the consultant radiographer had judged as clear all had clear margins and did not need any further surgery.

In the cohort of patients who required further surgery for involved margins, only 1 was identified to have involved margins on specimen radiography by the radiologist but not the surgeon.

\section{Discussion}

The results of this study show that there is fair congruence between the assessment of the surgeon and the radiographer in interpretation of the specimen $\mathrm{x}$-ray. In our unit the reported sensitivity of specimen $\mathrm{x}$-ray margin assessment by both surgeon and radiographer is lower than the literature (33\% vs $62 \%$ ). However, in this study wide confidence intervals are seen for sensitivity due to the low event rate. The negative predictive value in our unit of this assessment is very high (surgeon $89 \%$, radiographer $90 \%$ ). This may be of most importance in clinical practice to ensure adequacy of margins and avoidance of repeat operations. This observation shows that there can be a very high clinician confidence of accuracy where the specimen $\mathrm{x}$-ray is interpreted as showing clear margins.

For surgeon decision making this may be regarded as the most important conclusion from a specimen $\mathrm{x}$-ray as an intraoperative test to assess margin adequacy. Where specimen $\mathrm{x}$-ray reported either by a surgeon or radiologist/radiographer intra-operatively suggests close or involved margins a surgeon will subsequently take further margin cavity shaves at the first operation. This may increase the likelihood of clear margins on histological assessment with minimal patient morbidity even if that assessment of close/involved margins may be inaccurate. $2 / 22$ patients were saved a re-operation due to this practice. However, if a margin is assessed as clear on specimen $\mathrm{x}$-ray then no further cavity shaves are taken. So here if the test is interpreted incorrectly as negative then the opportunity to take shaves and therefore reduce the likelihood of a second surgery is missed.

Obtaining a specimen radiograph requires a greater use of resources including radiology equipment and radiologist/radiographer time. This study shows that a surgeon assessment of a specimen radiograph has a very high negative predictive value and with acceptable agreement to a radiologist/radiographer assessment.

The use of cabinet $\mathrm{x}$-ray systems, such as Faxitron, which is utilized in our unit, is observed in many breast units for intraoperative specimen radiography. Such systems will avoid the need for the specimen to be transported to the radiology department for assessment and then 
the delay for a radiologist/radiographer report to be undertaken and communicated to the operating surgeon.

The UK has real challenges with the recruitment, retention and necessary capacity of breast radiologists and radiographers to deliver a breast service. The reporting of specimen $\mathrm{x}$-rays is often then omitted from the routine workload of the radiologists to prioritise the need of this expertise. Although our study shows that radiologist interpretation of intra-operative specimen $\mathrm{x}$-rays can improve specificity $(63.46 \%$ vs $73.08 \%$ ) and positive (9.5 vs $12.5 \%$ ) and negative ( 89.2 vs $90.5 \%)$ predictive values we argue that clinically this is not significant regarding intraoperative decision making and avoiding repeat operations.

Specimen radiography has been shown to increase the complete excision rate at the initial operation [29] [21] and so reduce the need for breast cancer patients to undergo potentially avoidable repeat operations. In this study, 1 re-excision could have been avoided if breast radiology reporting had been accessible intra-operatively.

This study shows that the radiologist margin assessment in our institution of specimen radiography is comparable with the reported literature. The current literature offers no comparison with surgeon assessment of specimen radiography. The Kappa coefficient in our study of 0.25 showed a fair level of agreement between surgeon and radiologist. Previous studies showed that tumour grade, type and size did not influence margin assessment [30-31]. In this study, such conclusions could not be drawn due to the size of the patient cohort and the low positive margin rate.

The single surgeon series reviewed in this study reflects a practice with a low margin positivity rate $(5.08 \%)$ compared to the national trend of approximately $20 \%$ [32]. Undertaking this study for surgeons with a higher margin positivity rate and closer to the national average may allow for greater statistical analysis of a difference between surgeon and radiologist specimen $\mathrm{x}$-ray interpretation. Such a study may be considered to ensure non-inferiority between surgeon and radiologist specimen $\mathrm{x}$-ray when the event rate of positive margins is greater.

\section{Conclusion}

The accuracy of radiological assessment of involved margins in this study is comparable to that of current literature. There is fair agreement between surgeon and radiologist interpretation of specimen $\mathrm{x}$-ray for assessment of resection margins. The negative predictive value of margin assessment is very high between surgeon and radiologist. It has been argued that this outcome from this diagnostic test is the most clinically important in reducing re-operation rates.

The use of specimen X-ray reduces the rate of re-operations for positive resection margins. It can be recommended that surgeon assessment alone of the specimen is satisfactory and equivalent to radiological assessment in achieving this outcome. There is an increasing burden and reducing human resource within breast radiology departments in the UK. Omitting the need of the radiologist and radiology department by the use of cabinet $\mathrm{x}$-ray systems and surgeon only specimen $\mathrm{x}$-ray assessment can provide one solution to addressing this challenge without compromising patient care.

\section{Conflict of interest}

None declared

\section{Sources of funding}

None declared

\section{References}

1. Veronesi U, Cascinelli N, Mariani L, Greco M, Saccozzi R, et al. (2002) Twenty-year follow-up of a randomized study comparing breast-conserving surgery with radical mastectomy for early breast cancer. N Engl J Med 347: 1227-1232. [Crossref]

2. Poggi MM, Danforth DN, Sciuto LC, Smith SL, Steinberg SM, et al. (2003) Eighteenyear results in the treatment of early breast carcinoma with mastectomy versus breast conservation therapy. Cancer 98: 697-702. [Crossref]

3. Fisher B, Anderson S, Bryant J, Margolese RG, Deutsch M, et al. (2002) Twentyyear follow-up of a randomized trial comparing total mastectomy, lumpectomy, and lumpectomy plus irradiation for the treatment of invasive breast cancer. $N$ Engl J Med 347: 1233-1241. [Crossref]

4. Association of Breast Surgery at Baso 2009 (2009) Surgical guidelines for the management of breast cancer. Eur J Surg Oncol 35 Suppl 1: 1-22. [Crossref]

5. Cochrane RA, Valasiadou P, Wilson AR, Al-Ghazal SK, Macmillan RD (2003) Cosmesis and satisfaction after breast-conserving surgery correlates with the percentage of breast volume excised. Br J Surg 90: 1505-1509. [Crossref]

6. Asgeirsson KS, Rasheed T, McCulley SJ, Macmillan RD (2005) Oncological and cosmetic outcomes of oncoplastic breast conserving surgery. Eur J Surg Oncol 31: 817-823. [Crossref]

7. Houssami N, Macaskill P, Marinovich ML, Dixon JM, Irwig L, et al. (2010) Metaanalysis of the impact of surgical margins on local recurrence in women with earlystage invasive breast cancer treated with breast-conserving therapy. Eur J Cancer 46: 3219-3232. [Crossref]

8. Early Breast Cancer Trialists' Collaborative Group, 2011 (2011) Effect of radiotherapy after breast-conserving surgery on 10 -year recurrence and 15 -year breast cancer death: meta-analysis of individual patient data for 10801 women in 17 randomised trials. Lancet 378: 1707-1716. [Crossref]

9. Clarke M, Collins R, Darby S, Davies C, Elphinstone P, et al. (2005) Effects of radiotherapy and of differences in the extent of surgery for early breast cancer on local recurrence and 15-year survival: an overview of the randomised trials. The Lancet, 366 : 2087-2106. [Crossref]

10. Gøtzsche, PC, Nielsen M (2009) Screening for breast cancer with mammography. Cochrane Database Syst Rev 4.

11. Smith RA, Saslow D, Sawyer KA, Burke W, Costanza ME, et al. (2003) American Cancer Society guidelines for breast cancer screening: update 2003. CA Cancer J Clin 53: 141-169. [Crossref]

12. Rahusen FD, Bremers AJ, Fabry HF, van Amerongen AH, Boom RP, et al. (2002) Ultrasound-guided lumpectomy of non-palpable breast cancer versus wire-guided resection: a randomized clinical trial. Ann Surg Oncol 9: 994-998. [Crossref]

13. Pleijhuis RG, Graafland M, de Vries J, Bart J, de Jong JS (2009) Obtaining adequate surgical margins in breast-conserving therapy for patients with early-stage breast cancer: current modalities and future directions. Ann Surg Oncol 16: 2717-2730.

14. Medina-Franco H, Abarca-Pérez L, García-Alvarez MN, Ulloa-Gómez JL, RomeroTrejo C, et al. (2008) Radioguided occult lesion localization (ROLL) versus wireguided lumpectomy for non-palpable breast lesions: A randomized prospective evaluation. J Surg Oncol 97: 108-111. [Crossref]

15. Postma EL, Verkooijen HM, van Esser S, Hobbelink MG, van der Schelling GP, et al. (2012) Efficacy of 'radioguided occult lesion localisation' (ROLL) versus 'wireguided localisation' (WGL) in breast conserving surgery for non-palpable breast cancer: a randomised controlled multicentre trial. Breast Cancer Res Treat 136: 469478. [Crossref]

16. Nadeem R, Chagla LS, Harris O, Desmond S, Thind R, et al. (2005) Occult breast lesions: a comparison between radioguided occult lesion localisation (ROLL) vs. wireguided lumpectomy (WGL). Breast 14: 283-289. [Crossref]

17. Cabioglu N, Hunt KK, Sahin AA, Kuerer HM, Babiera GV, et al. (2007) Role of intraoperative margin assessment in patients undergoing breast- conserving surgery. Ann Surg Oncol 14: 1458-1471. [Crossref]

18. McCormick JT, Keleher AJ, Tikhomirov VB, Budway RJ, Caushaj PF (2004) Analysis of the use of specimen mammography in breast conservation therapy. Am J Surg 188: 433-436. [Crossref]

19. Kurniawan ED, Wong MH, Windle I, Rose A, Mou A, et al. (2008) Predictors of surgical margin status in breast-conserving surgery within a breast screening program. Ann Surg Oncol 15: 2542-2549. [Crossref] 
20. Kollias J, Gill PG, Beamond B, Rossi H, Langlois S, et al. (1998) Clinical and Radiological predictors of complete excision in breast conserving surgery for primary breast cancer. Aust N Z J Surg 68:702-706. [Crossref]

21. Blower E, Redmond E, Seward J, Harding-McKean C (2015) Has the use of in theatre intra-operative specimen X-ray reduced our re-operation rates in breast conserving surgery? Intern J Surg 23: S31-32.

22. The breast imaging and diagnostic workforce in the United Kingdom April 2016. Roy Coll Radiologists.

23. Campbell D (2016) Lack of NHS radiologists 'could cause delays to breast cancer diagnoses.

24. Field S (1996) UK radiology workforce survey - breast imaging services. Roy Coll Radiologists 45:10-12.

25. Duijm LE, Louwman MW, Groenewoud JH, van de Poll-Franse LV, Fracheboud J, et al. (2009) Inter-observer variability in mammography screening and effect of type and number of readers on screening outcome. Br J Cancer 100: 901-907. [Crossref]

26. Tonita JM, Hillis JP, Lim CH (1999) Medical radiologic technologist review: effects on a population-based breast cancer screening program. Radiology 211: 529-533. [Crossref]
27. Sumkin JH, Klaman HM, Graham M, Ruskauff T, Gennari RC, et al. (2003) Prescreening mammography by technologists: a preliminary assessment. AJR Am J Roentgenol 180: 253-256. [Crossref]

28. Torres-Mejía G, Smith RA, Carranza-Flores Mde L, Bogart A, Martínez-Matsushita L, et al. (2015) Radiographers supporting radiologists in the interpretation of screening mammography: a viable strategy to meet the shortage in the number of radiologists. BMC cancer 15: 410. [Crossref]

29. Van den Biggelaar FJ, Kessels AG, van Engelshoven JM, Flobbe K (2010) Diagnostic performance of breast technologists in reading mammograms in a clinical patient population. Int J Clin Pract 64: 442-450. [Crossref]

30. Buggi F, Mingozzi M, Curcio A, Rossi C, Nanni O, et al. (2013) Intra-operative radiological margins assessment in conservative treatment for non-palpable DCIS: correlation to pathological examination and re-excision rate. Springerplus 2: 243. [Crossref]

31. Rua C, Lebas P, Michenet P, Ouldamer L (2012) Evaluation of lumpectomy surgical specimen radiographs in subclinical, in situ and invasive breast cancer and factors predicting positive margins. Diagn Interv Imaging 93: 871-877. [Crossref]

32. Jeevan R, Cromwell DA, Trivella M, Lawrence G, Kearins O, et al. (2012) Reoperation rates after breast conserving surgery for breast cancer among women in England: retrospective study of hospital episode statistics. BMJ 345: e4505.

Copyright: $\mathbb{C} 2018$ Mylvaganam S. This is an open-access article distributed under the terms of the Creative Commons Attribution License, which permits unrestricted use, distribution, and reproduction in any medium, provided the original author and source are credited. 